\title{
Chapter 1: Ethics Engagement of the Dual-Use Dilemma: Progress and Potential
}

\author{
MICHAEL J. SELGELID
}

\section{Introduction}

During the past decade, the problem of dual-use research, science, and technology has been one of the most debated issues in discourse surrounding biological weapons and the bioterrorist threat, and a particularly controversial topic regarding science policy. The expression 'dual use' was historically used to refer to technology, equipment, and facilities that could be used for both civilian and military purposes. Conceived this way, dual-use technology is not necessarily something to worry about. To the contrary, this kind of technology was sometimes considered desirable from the standpoint of policymakers a way of killing two birds with one stone. Policymakers were nonetheless concerned about exporting such technologies to adversary countries.

In contemporary discourse the expression 'dual use' is usually used to refer to research, science and technology that can be used for both good and bad purposes. While almost anything can have multiple functions, current debates have been primarily concerned with bad purposes involving weapons - and, most commonly, weapons of mass destruction in particular (that is, where the consequences of malevolent use would be most severe). Of specific concern is the possibility that recent developments in the life sciences may enable development of a new generation of especially dangerous bioweapons. ${ }^{1}$

Such concerns are illustrated by a number of controversial experiments published during the past decade, such as the genetic engineering of a superstrain of vaccine-resistant mousepox, ${ }^{2}$ the artificial synthesis of a live polio

\footnotetext{
1 National Research Council 2004, Biotechnology research in an age of terrorism, Washington, DC: National Academies Press.

2 Jackson, R. J., Ramsay, A. J., Christensen, C. D., Beaton, S., Hull, D. F. and Ramshaw, I. A. 2001, ‘Expression of mouse interleukin-4 by a recombinant ectromelia virus suppresses cytolytic lymphocyte responses and overcomes genetic resistance to mousepox', Journal of Virology, vol. 75, pp. 1205-10.
} 
virus from scratch, ${ }^{3}$ and the reconstruction of the 1918 Spanish Flu virus; ${ }^{4}$ and the general phenomenon of converging technologies, such as synthetic biology and bionanotechnology. ${ }^{5}$ Given these and other developments, life scientists are currently in a situation very similar to that faced by atomic physicists early in the twentieth century, when key discoveries that enabled production (and use) of the first atomic bombs were made. Like nuclear technology, powerful technologies made possible by the rapid progress of the life sciences may have great benefits for humankind, but they could also have disastrous consequences if employed by those bent on causing destruction.

The dual-use phenomenon raises important questions about the responsibilities of scientists, research institutions, the scientific community, publishers, and policymakers. Responsible actors at each of these levels should aim to promote the progress of science insofar as such progress will benefit humanity; but they should aim to avoid outcomes where developments ultimately result in more harm than good. One popular idea in recent debates about the dual-use problem is that we should aim for policy that strikes a balance between the goal to promote scientific progress (and the good things thereby enabled) and the goal to protect security. ${ }^{6}$

While that sounds plausible, open questions remain: What, for example, would be an appropriate balance between scientific progress and security; and how could such a balance be attained in practice? Should we rely on voluntary self-governance, or is more governmental oversight called for? Perhaps unsurprisingly, the scientific community is strongly in favour of 'bottom-up' solutions to dual-use research governance (that is, voluntary self-governance). It is commonly held that new codes of conduct addressing responsibilities related to dual-use research should be adopted, and that scientists should be further educated about the potential dual-use implications of their work; but scientists generally resist the idea that solutions to problems raised by the dualuse phenomenon should involve increased governmental control over scientific enterprise. Among other things, they argue that autonomy is essential to science progress and that governmental interference would be both counterproductive (unnecessarily stifling important and beneficial research) and violate the right to freedom of inquiry (academic freedom) and (in the case of governmental censorship of dangerous discoveries) freedom of speech.

\footnotetext{
3 Cello, J., Paul, A. V. and Wimmer, E. 2002, 'Chemical synthesis of poliovirus cDNA: Generation of an infectious virus in the absence of natural template', Science, vol. 9, pp. 1016-18.

4 Tumpey, T. M., Basler, C. F., Aguilar, P. V., Zeng, H., Solórzano, A., Swayne, D. E., Cox, N. J., Katz, J. M., Taubenberger, J. K., Palese, P. and García-Sastre, A. 2005, 'Characterization of the reconstructed 1918 Spanish influenza pandemic virus', Science, vol. 310, pp. 77-80.

5 Institute of Medicine and National Research Council 2006, Globalization, biosecurity and the future of the life sciences, Washington, DC: National Academies Press.

6 National Research Council 2004, op cit.
} 


\section{Bioethics' Neglect of Dual-Use Discourse}

The main parties to debates about the responsibilities of scientists and other actors - and relevant debates about the governance of dual-use research have, to date, mainly been scientists and security experts. With the exception of a small and recently emerging literature, notably absent from such debates has been the voice of (bio)ethicists in particular. This is unfortunate partly because the dual-use dilemma is, by its very nature, an ethical one. Talk about 'beneficial and malevolent' or 'good and bad' uses of science and technology, the 'promotion of benefits and the avoidance of harms', and the 'responsibilities' of actors all fall squarely within the realm of ethics: the discipline explicitly concerned with issues of good and bad, right and wrong, and the duties and responsibilities of human beings.

Above, I indicated that a plausible and popular notion is that we should aim for policy that strikes a balance between the goal to promote security and the goal to promote scientific progress; the idea being that heavy regulation of science might promote security at too high a price with regard to scientific progress and that too little oversight might facilitate science progress at too high a price with regard to security. This raises questions about the (nature of the) value of security and the (nature of the) value of scientific progress - and questions about how such values should be balanced against one another in cases of conflict. For example, should security be considered to be merely of instrumental value something that should be valued only insofar as it promotes (other) things that are considered to be intrinsically valuable (that is, valued for their own sake)? Or is security itself intrinsically valuable? These are all ethical questions.

Questions about norms, values and what social policy should be are precisely the kinds of things that ethics is concerned with. While science is concerned with what is the case; ethics, by definition, is concerned with what should or ought to be the case. Although their contribution to debates about dual use is (for obvious reasons) absolutely essential, scientists and security experts have no special expertise for analysis of normative questions such as these, and so more input from ethicists is crucial. A broader, more interdisciplinary discussion about the dual-use problem is wanted.

Given that bioethicists have had so much to say about research ethics in general and the social implications of genetic research and science in particular, it is surprising that they have not been more actively engaged in discussions about dual-use life-science research. Discourse surrounding research ethics has traditionally focused on the protection of human and animal subjects rather than dangers associated with the potential malevolent use of research findings. Recent decades have witnessed enormous attention from bioethicists 
to 'ethical, legal, and social implications' (ELSI) of the genetics revolution. In the early days of DNA recombinant technology, environmental safety was a focus of bioethics discussion regarding genetics research. More recently ELSI discourse surrounding genetics has focused on the (clinical) safety of genetic therapy (or research pertaining thereto), genetic determinism, genetic testing, genetic discrimination, genetic enhancement, selective reproduction (that is, eugenics), cloning, stem-cell research, DNA fingerprinting, and the patenting of genetic sequences. That these have, to date, undeniably been the standard topics of ELSI discourse is quickly revealed by examination of titles, abstracts, tables of contents, and indexes of texts concerned with ELSI issues surrounding genetics. Though concern regarding dual-use life-science research largely relates to genetics in particular, and although the weapons implications of genetics may turn out to be the most serious (ethical and social) consequence of the genetics revolution, those concerned with the ethical implications of genetics have traditionally (and until only very recently, and in exceptional cases) been almost entirely silent about the potential weapons implications of genetics.

The lack of bioethics' attention to this topic is partly revealed by Robert Cooke-Deegan's canonical history of the Human Genome Project, The Gene Wars. ${ }^{7}$ Cooke-Deegan's volume explicitly includes coverage of the politics and ethical debate surrounding the new genetics, and it even includes a chapter entitled 'Genes and the Bomb'. Despite the links it draws between genetics and atomic weapons, however, the volume never mentions the biologicalweapons implications of genetics. This is odd partly because (as Cooke-Deegan demonstrates) important origins of the Human Genome Project are found in the US Department of Energy and the Los Alamos laboratories where the first atomic bombs were made. Such organisations were interested in genetics partly because they wanted to learn about radiation's effects on genetic material. Given these organisations' explicit concern with (albeit nuclear) weapons of mass destruction, not to mention their governmental and military affiliations, one expects that those involved would have recognised and considered the weapons potential of the genetics revolution very early on. Therefore, it is surprising that discussion of such issues is not included in Cooke-Deegan's commentary on debates surrounding socially controversial aspects of genetics.

It is commonly said in ELSI discourse that the power of genetics is comparable to the power of atomic physics, and that we thus need more ethical discussion and reflection about the former than the latter received when the first atomic bombs were made and used - so that more socially responsible decisions about science can be made in genetics than were made regarding nuclear energy. However, the usual topics of ELSI discourse reveal that weapons development is not what

7 Cooke-Deegan, R. 1994, The gene wars: Science, politics, and the human genome, New York: Norton. The discussion that follows is not meant to be a critique of Cooke-Deegan. 
those concerned with the ethics of genetics have had in mind. At the time of writing (in early 2010), an enormous number of journal articles and books on ethics and genetics have been written; but, aside from a few recent exceptions, explicitly ethical literature (authored by ethicists and in books and journals primarily concerned with ethics) includes little if any discussion of genetics' potential role in weapons making.

This raises interesting historical and sociological questions about the discipline of bioethics. How, for example, should bioethics' long-term failure to address the weapons implications of genetics be explained? One possibility is that bioethicists were, for a long time anyway, simply unaware of the weapons potential of genetics. However, if this is correct, why didn't scientists and policymakers bring such issues to the attention of bioethicists working on ELSI issues? If bioethicists (who are not usually scientists) were not aware of the reality and seriousness of the weapons potential of genetics, this is presumably at least partly because no one made them aware. Part of the explanation why such dangers were not highlighted earlier may be that the spectre of biological weapons was largely overshadowed (in the minds of scientists, other academics, and policymakers) by the nuclear threat during the Cold War. ${ }^{8}$ Be that as it may, this would not imply that the biological weapons threat should have been considered less far-fetched and worthy of discussion than many of the (often largely science-fiction) issues that bioethicists have focused on ${ }^{9}$ and which one might also have expected to be overshadowed by more pressing concerns. Another reason may be that most scientists have themselves been largely unaware of the dual-use phenomenon. Such lack of awareness has been demonstrated by empirical research. ${ }^{10}$ (One would have thought, however, that enough scientists would have been conscious of the weapons potential of genetics to alert bioethicists to potential dangers. As indicated above, at least those involved in the Department of Energy and Los Alamos laboratories should have been aware of the possibility, so why would they not have brought the issue to the attention of those concerned with ethical issues associated with genetics?)

A disturbing possibility is that a conscious decision was made by leading scientists not to raise the issue of biological weapons at the Asilomar conference during the $1970 \mathrm{~s}^{11}$ and that a conspiratorial silence on the part of scientists remained long afterwards. If this really is an important part of the explanation

8 Malcolm Dando, personal communication.

9 Such as much of the recent literature regarding human enhancement (for example, radical life extension).

10 Dando, M. R. and Rappert, B. 2005, 'Codes of conduct for the life sciences: Some insights from UK academia', Briefing Paper No. 16, Department of Peace Studies, University of Bradford, available: http://www. brad.ac.uk/acad/sbtwc/briefing/BP_16_2ndseries.pdf [viewed 18 October 2009].

11 Rogers, M. 1975, 'The Pandora's box congress', Rolling Stone (19 June), p. 37, cited in Garfinkel, M. S., Endy, D. and Epstein, G. L. 2007, Synthetic genomics: Options for governance, available: http://www.jcvi. $\mathrm{org} / \mathrm{cms} /$ fileadmin/site/research/projects/synthetic-genomics-report/synthetic-genomics-report.pdf [viewed 5 April 2010]. 
of bioethics' neglect of dual-use issues, we should perhaps be wary about calls for voluntary self-governance by scientists. That is, we might be reluctant to trust scientists if they previously failed to disclose potential dangers of their work and, as a result, an important public debate about a crucial ELSI genetics topic was delayed by a decade or more.

Public debate about ELSI implications of genetics was in full force during the 1990s largely as a result of attention raised by bioethicists. However, public debate regarding dual-use implications of the life sciences did not gain prominence until early in the twenty-first century. Furthermore, this was arguably primarily due to the events of 11 September 2001 and the anthrax attacks that followed. For the most part, bioethicists neither played a major role in bringing to prominence, nor contributing to, the debates that have since ensued.

Thus, a remaining puzzle about bioethicists' lack of attention to the dualuse dilemma is why they have not further engaged in discussion of weapons implications of science since the time they most probably became aware of them. For example, the controversial experiments mentioned at the start of this chapter received a great deal of media attention, so bioethicists presumably would have heard about them. An important part of the explanation of neglect may thus be bioethicists' lack of familiarity and engagement with security issues - as opposed to clinical or medical matters - in general. The significance of the dualuse problem provides one reason why bioethicists should, in the future, become more engaged with issues pertaining to security. The security implications of infectious diseases in general provide another. Those concerned about dual-use research often advocate increased education of scientists regarding the dual-use potential of their work. However, in the aim to achieve a more informed ethical debate about research we should perhaps also advocate increased education of bioethicists regarding security. Security raises crucial bioethical issues, but bioethicists have devoted alarmingly little attention to such matters.

\section{Ethics Discourse to Date}

Despite the long lamentation above, the good news is that there have recently been at least a few exceptions to the rule that ethics literature has neglected the problem of dual-use research. There is now an emerging, growing body of explicitly ethical literature on this topic, and this is hopefully in the process of reaching a critical mass. ${ }^{12}$ Much of the relevant literature has focused on

12 See Resnik, D. and Shamoo, A. E. 2005, 'Bioterrorism and the responsible conduct of biomedical research', Drug Development Research, vol. 63, pp.121-33; Green, S. K. et al. 2006, 'Guidelines to prevent malevolent use of biomedical research', Cambridge Quarterly of Healthcare Ethics, vol. 15, pp. 432-47; Selgelid, M. J. 
questions about the ethical responsibilities of scientists in particular. For example, to what extent would scientists be responsible for adverse outcomes that might result from the malevolent use of their research by other actors and to what degree are they obligated to prevent misuse - perhaps by refraining from engaging in potentially dangerous research or publication when potentially dangerous discoveries are made?

Such discussion of social responsibility is important, especially given the history of scientific culture. ${ }^{13}$ At various times in history, to a greater or lesser degree, science has been characterised as neutral, apolitical, and/or values-free. Common ideas among scientists (and others) have been that science involves an impartial pursuit of knowledge and/or that scientific knowledge is inherently good. ${ }^{14}$ Another frequently heard idea, especially in debates about the social responsibility of scientists in the context of nuclear weapons, is that knowledge, technology and other fruits of science are neither good nor bad — but, to the contrary, it is the uses to which they are applied that are good or bad. Last but not least, it was argued that although the prevention of harmful uses of knowledge and technology may be important, scientists themselves do not have the responsibility, expertise or power to prevent malevolent applications of their work from occurring. ${ }^{15}$ Rather than an obligation of scientists, the argument goes, the obligation to prevent harmful applications of knowledge falls on policymakers (who have — or, at least, should have — the requisite responsibility, expertise and power). If scientists do not produce anything that is inherently bad, and these other ideas are correct, one might think that scientists engaged in legitimate research are not responsible for harmful outcomes resulting from their morally neutral pursuits and products. Those who employ knowledge in a malign manner, and policymakers who fail to prevent them from doing so, would be responsible for bad outcomes; and scientists would remain innocent.

2007, 'A tale of two studies: Ethics, bioterrorism, and the censorship of science', HastingsCenter Report, vol. 37(3), pp. 35-43; Jones, N. 2007, 'A code of ethics for the life sciences', Science and Engineering Ethics, vol. 4, pp. 25-43; Miller, S. and Selgelid, M. J. 2008, Ethical and philosophical consideration of the dualuse dilemma in the biological sciences, Dordrecht, NE: Springer; Ehni, H. J. 2008, 'Dual use and the ethical responsibility of scientists', Archivum Immunologiae et Therapiae Experimentalis, vol. 56, pp.147-52; Kuhlau, F., Eriksson, S., Evers, K. and Hoglund, A. T. 2008, 'Taking due care: Moral obligations in dual-use research', Bioethics, vol. 22(9), pp. 477-87; Dando, M. 2009, 'Bioethicists enter the dual-use debate', Bulletin of the Atomic Scientists, 26 April, available: http://www.thebulletin.org/web-edition/columnists/malcolm-dando/ bioethicists-enter-the-dual-use-debate [viewed 20 January 2010]; Kuhlau, F., Hoglund, A. T., Evers, K. and Eriksson, S. 2009, 'A precautionary principle for dual-use research in the life sciences', Bioethics (online prior to printing: doi:10.1111/j.1467-8519.2009.01740.x); Special Issue Section on The Advancement of Science and the Dilemma of Dual Use (2010), Science and Engineering Ethics, vol. 16(1).

13 Jones 2007, op. cit.

14 Kitcher, P. 2001, Science, truth, and democracy, New York: Oxford University Press.

15 Bridgeman, P. W. 1947, 'Scientists and social responsibility', The Scientific Monthly, vol. 65(2), August, pp. $148-54$. 
However, the idea that scientists should be fully divorced from responsibility for consequences of their well-intentioned research is not that tenable. If one foresees that his work is likely to be used in ways that cause more harm than good and proceeds regardless (without doing anything to forestall the harm in question), then he will be implicated in the bad consequences that ensue. If I knowingly enable a malevolent actor to cause harm, I am at least partly responsible for harm that results. We should go farther by saying that scientists have a duty to consider the uses to which their work will be applied, and that they bear significant responsibility for harmful outcomes that are foreseeable whether or not they are foreseen by the scientists in question. The point here is that scientists have a responsibility to be aware and reflect on the ways in which their work will be used. The failure to reflect or foresee the foreseeable should be considered negligence. In the context of weapons of mass destruction, such negligence could cause grave harm. If a scientist carelessly conducts and publishes dangerous research in an environment where adequate policies to prevent misuse are not in place, and a malevolent actor uses this research to cause great harm, it would be reasonable to conclude that the scientist, relevant policymakers, and (of course) the malevolent actor, are all partly responsible for damage done.

A virtue of much of the emerging dual-use ethics literature is that it takes seriously the idea that individual scientists have significant responsibilities regarding the prevention of harm resulting from malevolent use of their research. However, it might be argued that at least some authors have not taken a sufficiently clear and/or strong stand on such issues. For example, while questioning the specific obligations of scientists in the context of dual-use research, Kuhlau et al. (in the first paper on dual use in the journal Bioethics, published in 2008) argue that scientists have a duty to 'consider negative implications of research' and 'to consider whether to refrain from publishing or sharing sensitive information when the information is of such a character that it could invite misuse'. ${ }^{16}$ They do not, however, go further by saying how one should act on his or her deliberations. The mere duty to consider the consequences of one's actions is presumably too weak if one is not further obligated to refrain from the actions in question if certain expectations result from the consideration in question. Not only do they fail to say how a scientist is obligated to act based on consideration of the results of a potential research project or publication, they do not clearly hold that scientists have any obligation beyond the act of consideration itself. One might have expected, for example, that scientists have obligations to consider the implications of their research and publications and obligations to refrain from the research or publication when harms are (reasonably) expected

16 Kuhlau et al. 2008, op. cit., pp. 484-5. 
to outweigh benefits, or something like that. In the context of research, at least, perhaps this is what these authors have in mind, but it is odd they do not say so more explicitly.

In the context of publication, in any case, Kuhlau et al. offer resistance to the idea that scientists clearly have a strong obligation to refrain from publishing dual-use discoveries with dangerous implications, but their analysis here conflates separate issues:

[W]e need to recognise such values as publishers' freedom of press and scientists' legal right to publish. It is therefore controversial to propose an obligation inflicting too many restrictions. Restrictions on publications have several implications, for example, for scientists' need to be able to replicate results in order to conduct further research, build upon the results of others, and develop and maintain a scientific record and reputation. ${ }^{17}$

The problem is that this kind of concern confuses the question of what a researcher has a moral obligation to refrain from doing with the question of what a researcher should be legally prevented from doing. Whether or not censorship by government of dual-use research would ever be called for is an important question. However, one could consistently believe there are cases where scientists would have a moral obligation to refrain from publication without thinking the obligation should be enforced by law or governmental censorship. The legal right to freedom to publish is not incompatible with a moral obligation not to publish because not all obligations are (or should be) enforced by law. What one is morally required to do and what one is legally required to do are distinct but related questions that should be treated separately. I might think I clearly have a strong moral obligation to walk my dog twice a day and say my prayers before I go to bed at night, but this would not imply that I think the law should require me or anyone else to do such things. Proposing that scientists have obligations to refrain from publication in problematic cases simply does not entail support of censorship, as is suggested by Kuhlau et al. ${ }^{18}$

17 Ibid.

18 Kuhlau et al. conclude (p. 485) that 'the duty not to publish or share sensitive information' is 'potentially reasonable, although phrased too much in the negative'. Given this, and their final suggestion that censorship by government might on occasion be called for after all, it is not entirely clear what specific duty beyond the 'duty to consider whether to refrain from publication' they are arguing for. Rather than defending or establishing a stronger specific duty of scientists in the context of publication, their argument appears to be more focused on defending self-governance of scientists, at least in most cases. 


\section{The Way Forward}

Two things remain to be said about the apparent focus of much of the emerging ethical literature on the duties and responsibilities of individual scientists. First, although the dual-use phenomenon undoubtedly raises crucial ethical questions about the duties and responsibilities of individual scientists, it is by no means an ethical issue for scientists alone. The phenomenon of dualuse research, science, and technology also calls for important ethical decisionmaking by actors (with duties and responsibilities) at other levels. Research institutions (insofar as they are at liberty) must decide how to oversee activities within their confines and whether or not to provide (and perhaps require) relevant education. Scientific associations need to decide whether or not and/ or how to address dual-use research in codes of conduct; and they must decide whether or not and/or how to enforce such codes on members. Publishers need to decide what to publish and/or what screening mechanisms to put into place. And governments must decide whether or not and/or how to impose restrictions on dual-use research and technology. Governmental regulations could, among other things, potentially call for mandatory reporting of dual-use research to committees for clearance before experiments are conducted or published and/ or compulsory education of researchers about the dual-use phenomenon and/or ethics. Finally, funders of scientific research must decide what research to fund; and they must decide whether or not relevant education, adherence to codes of conduct and/or reporting of dual-use research to committees before experiments are conducted or published should be conditions of individual researchers' or research institutions' eligibility for funding. The dual-use phenomenon raises ethical issues for decision-makers at each of these levels, because they all face the ethical question about how to strike a balance between the protection of security and the promotion of academic freedom and/or scientific progress (assuming these things will sometimes come into conflict ${ }^{19}$ ). More detailed ethical analysis of the responsibilities of these other actors is therefore important.

Although governmental regulation of research is controversial for reasons considered at the beginning of this paper, it may be imprudent to rely too heavily on voluntary governance of scientists or the scientific community even if we gain more clarity about the social responsibilities of scientists. One reason that mandatory measures might be called for is that scientists may not always have sufficient expertise for judging the security dangers that might result from their research and/or publications. Responsible decision-making requires assessment of the security risks and social benefits likely to arise from any given experiment or publication. Scientists, however, usually lack training in security studies and thus have no special expertise for assessing security risks

19 Some might argue that free or open science would provide the best means to maximisation of security. 
in particular. In some cases they are systematically denied access to information crucial to risk assessment. For example, in the case of the mousepox study a primary concern was the possibility of proliferation of smallpox from former Soviet weapons stockpiles of the virus - that is, because bioweaponeers would need access to the virus in order to apply the mousepox genetic engineering technique to it in the hope of producing a vaccine-resistant strain of smallpox. However, any detailed information about smallpox proliferation is classified information to which the vast majority of scientists would not have access. Thus, in this important case, which has been a paradigm example of dual-use research of concern, ordinary scientists would be unable to make an informed assessment of the risks of publication.

An additional reason not to rely too heavily on voluntary self-governance is that conflicts of interest may often come into play. For example, given that career advancement in science is largely determined by publication record, a researcher may often have self-interested reasons for publishing potentially dangerous findings even when this might not be in society's best interests, all things considered. ${ }^{20}$

A second reason why ethical analysis of dual-use research should not focus too heavily on social responsibilities of scientists is that their duties (regarding whether or not to pursue a particular path of research or publication) cannot be determined in a vacuum. What exactly an individual should or should not do partly depends on actions taken by other actors at other levels in the science governance hierarchy.

Given the ultimate aim to avoid the malevolent use of dual-use technologies, it is important to recognise various stages in the 'dual-use pipeline' where preventative activities might take place, or regulations might operate. First, there is the conduct of research that leads to dual-use discoveries. One way to prevent malevolent use is thus to prevent the most worrisome experiments from taking place to begin with. A second way to prevent malevolent use would be to prevent dissemination of dangerous discoveries after they are made - that is, by not publishing them oneself (self-censorship), or by stopping others from publishing them (censorship). A third way would be to prevent malevolent use by limiting who has access to dual-use technologies and materials such as 'select agents' or potentially dangerous DNA sequences, requiring licensing of those using such technologies and materials, registration of relevant equipment, and so forth. A fourth way would be to strengthen the Biological and Toxin Weapons

20 Selgelid, M. J. 2007, 'A tale of two studies: Ethics, bioterrorism, and the censorship of science', HastingsCenter Report, vol. 37(3), pp. 35-43. 
Convention via the addition of verification measures. This would at least help prevent state actors from using legitimate science for the promotion of offensive biological-weapons programmes.

The point here is that the question of whether or not a researcher has a duty to refrain from pursuing a particular project or publishing a particular study partly depends on what preventative mechanisms are in place further down the 'dual-use pipeline'. For example, if one discovers how to synthesise a particularly contagious and/or virulent pathogen, the propriety of publishing this partly depends on whether regulatory measures that would prevent this finding from being employed by malevolent actors have been implemented. For instance, if there were stronger controls over access to the technologies and materials (for example, DNA sequences) required by others to reproduce such a pathogen and/or if the BTWC was strengthened by the addition of verification measures, the dangers of malevolent use arising from such a publication would be lower than otherwise. Thus, whether or not a researcher would have a duty not to publish in such a scenario, assuming they were at liberty to do so, at least partly depends on whether or not policymakers have fulfilled their duties to put adequate preventative measures in place.

In addition to further expanding discussion beyond the responsibilities of individual scientists, there are additional fruits to hope for when ethicists more actively engage with the dual-use problem. There are obvious ways in which it raises issues similar to (or overlapping with) those discussed in ethical debates about the doctrine of double effect and the precautionary principle. Whether or not either of these is plausible or correct, the well-developed discourse surrounding them would presumably shed light on the ethics of dualuse research. Rational decision theory and discourse about 'acts and omissions' likewise address relevant issues. The point is that a long, rich history of ethical debate in these and other areas might fruitfully be brought to bear on the dual-use problem if those with expertise in these and other areas of ethics only applied their minds to it. To date, it is safe to say, rigorous ethical analysis of the dual-use dilemma has only scratched the surface. 